\title{
Combination of ovarian endometrioid carcinoma and yolk sac tumor in postmenopausal women: a case report
}

S. Gon Ribeiro', H. Helber Alkalay¹, P. Taranto1, M. Cristófalo Martello², F. Maluf ${ }^{1}$

1. Hospital Israelita Albert Eistein 2. Faculdade de Ciências Médicas da Santa Casa de São Paulo

\section{OBJECTIVE}

Little is known about Ovarian Yolk Sac Tumors (YSTs) in postmenopausal female. To enhance scientific knowledge about this tumor, we describe a 64 years old woman with YSTs coexisting with ovarian epithelial tumor, focusing on diagnosis and treatment.

\section{METHOD}

Literature review and medical record

\section{CASE REPORT}

We describe a 64-year-old postmenopausal female, with an ovarian endometrioid carcinoma (FIGO IA/G3). The patient was started on adjuvant chemotherapy with 6 cycles of carboplatin and paclitaxel. After adjuvant chemotherapy, her scans reveled progressive disease in the liver which biopsy showed poor differentiated epithelioid neoplasia positive for SALL4, indicating a YSTs. We started on chemotherapy with BEP with 3 cycles, with decrease of tumor markers. However, despite initial clinical and laboratorial improvement, patient progressed to death in July.

Table 1: Positive immunohistochemical tests for YSTS

\begin{tabular}{|c|c|l|}
\hline Marker & Antibody & \multicolumn{1}{c|}{ Result } \\
\hline TTF-1 & 8 G7G3/1 & POSITIVE (rare cells) \\
\hline COX-2 & CDX-2 & POSITIVE (rare cells) \\
\hline GATA-3 & L50-823 & POSITIVE \\
\hline $\begin{array}{c}\text { Citoqueratin } \\
\text { AE-1/AE-3 }\end{array}$ & AE-1/AE-3 & POSITIVE (Strong) \\
\hline P40 Protein & Polyclonal & POSITIVE \\
\hline CD10 & $56 C 6$ & POSITIVE (focal) \\
\hline Glypican3 & Polyclonal & POSITIVE \\
\hline INI-1 & MRQ-27 & POSITIVE \\
\hline
\end{tabular}

Other negative markers tested: citoqueratin 7 and 20, PAX-8, Estrogen and progesterone receptor, HER2, Cromatogranin A, Sinaptofisia, Arginase, Mamoglobin, CD31, ERG, Citoceratin 5/6, GFAP, S100, Calponin, GCDFP-15, WT-1, PLAP, AML, Melan-A, Myo-D1, Miogenin, Desmin, Heppar
Figure 1: Multiple liver nodules, progressive disease.

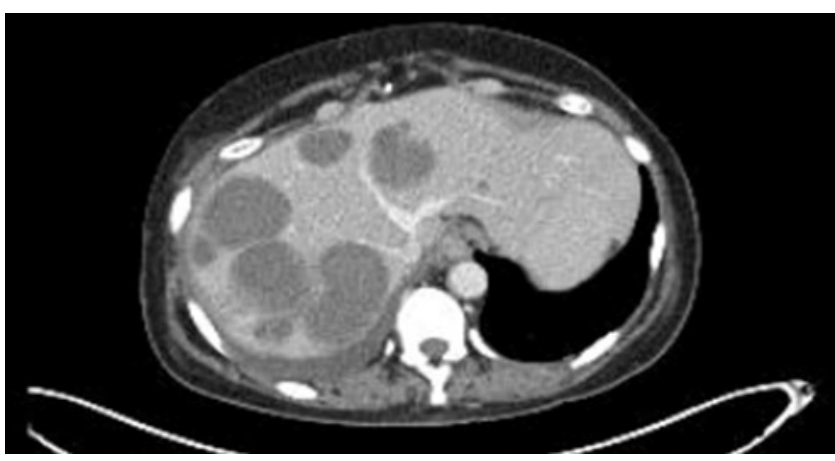

Figure 2: Tumoral marker evolution in diagnosis, after chemotherapy and disease progression. In order, latic dehydrogenase, beta-HCG and alpha fetoprotein.

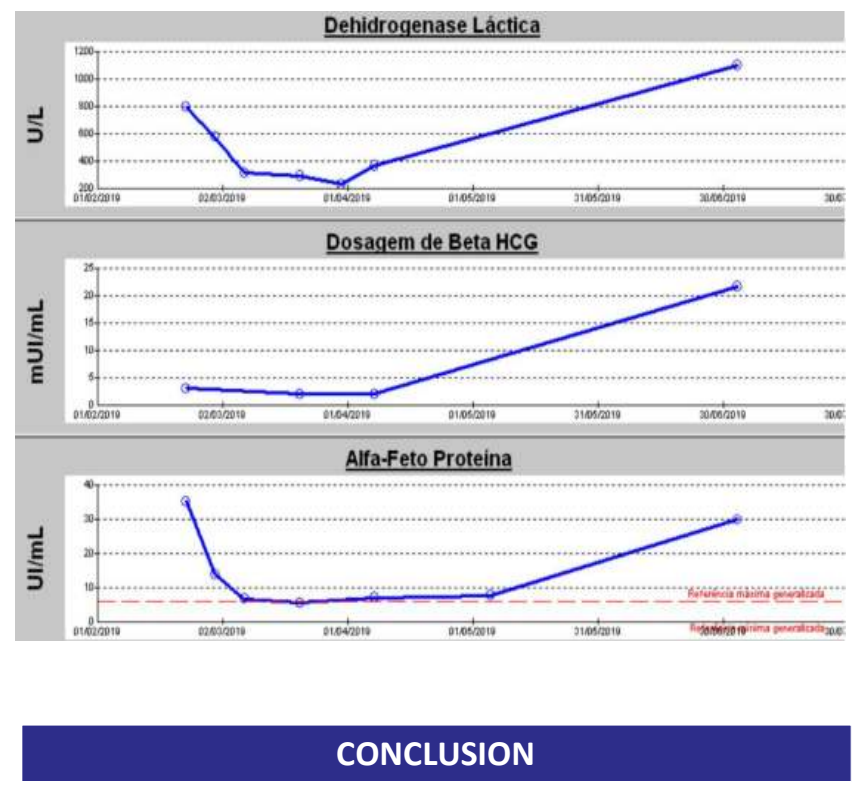

YSTs represent approximately $20 \%$ of all malignant germ cell tumors of the ovary and typically occur in young women ${ }^{1}$ Germinal cell neoplasm arise from an ovarian epithelial neoplasm is an extremely rare presentation in postmenopausal woman, with aggressive behavior ${ }^{2}$. The recognition of specific subtype is essential to determine treatment decisions and prognosis. 